\title{
openheart Determinants of walking fitness in patients with heart failure attending cardiac rehabilitation
}

\author{
Patrick Doherty, ${ }^{1}$ Alexander Stephen Harrison, ${ }^{1}$ Rashed Hossain ${ }^{2}$
}

To cite: Doherty P, Harrison AS, Hossain R. Determinants of walking fitness in patients with heart failure attending cardiac rehabilitation. Open Heart 2019;6:e000866. doi:10.1136/ openhrt-2018-000866

Received 28 May 2018 Revised 30 November 2018 Accepted 9 December 2018
(D) Check for updates

(C) Author(s) (or their employer(s)) 2019. Re-use permitted under CC BY. Published by BMJ.

${ }^{1}$ Department of Health Sciences, University of York, York, UK ${ }^{2}$ Cardiology department, York Teaching Hospitals NHS Foundation Trust, York, UK

Correspondence to Dr Patrick Doherty; patrick. doherty@york.ac.uk

\section{ABSTRACT}

Introduction Patients with heart failure (HF) attending cardiac rehabilitation (CR) benefit in terms of improved quality of life, physical fitness and reduced hospital admissions. Too few patients with HF attend CR and little data exist on the characteristics of those who do especially in respect of physical fitness. This study evaluates the extent by which clinical and demographic factors determine walking fitness in patients with a primary diagnosis of HF.

Methods Clinical data from the British Heart Foundation National Audit of Cardiac Rehabilitation identified 1519 patients with HF who completed an incremental shuttle walk test (ISWT). Stepwise regression accounting for age, gender and multiple potential confounders assessed their contribution to total walking distance.

Results Mean age was 64.5 (SD 12.70) years with a range of ISWT distances across gender and associated comorbidities from 215 to $282 \mathrm{~m}$. Walking distance reduced by $4.9 \mathrm{~m}$ for each year increase in age above mean age $(p<0.001)$. After accounting for confounders, females walked $42.1 \mathrm{~m}$ less than males $(p \leq 0.001)$. Pulmonary disease and the existence of depression was associated with a 39.3 and $52.2 \mathrm{~m}$ reduction in walking distance, respectively. Body mass index $>30$ was associated with $28.5 \mathrm{~m}$ reduction in walking distance $(p<0.001)$. HF severity failed to improve the regression model fit or achieve significance in the analysis Conclusions Age, gender and the presence of pulmonary disease or depression were highly significant factors in predicting walking fitness in patients with HF. The study also produced a set of reference values based on these four factors to aid the interpretation of walking fitness in patients with $\mathrm{HF}$.

\section{INTRODUCTION}

Cardiac rehabilitation (CR) for patients with coronary heart disease and those with heart failure (HF) is a clinically effective intervention that has yet to achieve optimal uptake in routine clinical practice. ${ }^{1-3}$ The stated ambition of NHS England is to improve uptake from $45 \%$ in 2014 to greater than $65 \%$ by 2020 which is an initiative that aligns with the National Institute for Health and Care Excellence guidance recommendations in the $\mathrm{UK}^{45}$ and international guidance. ${ }^{6}$ Cardiologists

\section{Key messages}

What is already known about this subject?

- Patients with heart failure should be referred to cardiac rehabilitation; however, less than $20 \%$ of eligible patients access such services.

- Exercise training and physical activity have been shown to benefit patients, yet too few programmes assess fitness prior to starting rehabilitation.

- Little is known about which clinical and patient characteristics determine fitness.

What does this study add?

- This study is the first to determine the extent by which comorbidities determine walking fitness in patients with a primary diagnosis of heart failure.

How might this impact on clinical practice?

- These findings have led to the development of walking fitness reference values which can be used by clinicians and patients to understand their level of fitness and help set realistic goals as part of their cardiac rehabilitation programme and long-term self-management.

and cardiac nurses play a fundamental role in the early treatment and management of heart disease and they represent the primary source of referral to CR. ${ }^{8}$

National audit data from the $\mathrm{UK}^{3}$ show that uptake to CR is around $50 \%$ for patients with acute coronary syndrome and equivalent to one-third in European and American CR programmes. ${ }^{9}{ }^{10}$ The situation is much worse for patients with HF where uptake is less than $20 \%$ of all eligible patients in the $\mathrm{UK}^{3}{ }^{11}$ Referral to CR for patients with HF has yet to become routine practice with most programmes already stretched by the sheer volume of patients attending through the conventional cardiology referral pathways. ${ }^{3} 12$

We hypothesise that one of the reasons so few patients with HF attend CR and many programmes are unable to recruit patients with $\mathrm{HF}$ is, in part, due to a perception that 'exercise training and rehabilitation' are at odds with a patient's diagnosis of HF. There 
is an urgent need to create a more realistic view of what a patient with HF can achieve in terms of physical exercise and fitness. Although clinical trial data on HF exist suggesting what is possible in terms of maximal exercise capacity, obtained from cardiopulmonary exercise testing (CPET), this tends to be based on an exclusive population that are much younger, by as much as 11 years, and have fewer comorbidities ${ }^{1}$ compared with patients who attend routine practice $\mathrm{CR} .{ }^{3}$

The incremental shuttle walk test (ISWT) is the most commonly used test of functional physical fitness in the UK. ${ }^{3}$ Although the ISWT does not represent a "criterion maximal test', of exercise capacity it is a recommended submaximal surrogate measure of exercise capacity ${ }^{13}$ that is positively validated against CPET. ${ }^{14}$ Some studies have used the ISWT to investigate potential determinants of walking fitness in conventional cardiac patients ${ }^{15} 16$ identifying age, height, body mass index (BMI) and the presence of diabetes as significant predictors of distanced achieved. The New York Heart Association (NYHA) Functional Classification is an established symptom and function-aligned measure, classifying the extent of HF severity in patients, yet has not been investigated for its role in determining walking fitness as measured by the ISWT in HF.

This study aims to investigate and assess the strength of association between walking fitness and relevant patient demographics, risk factors, comorbidities and severity of HF. Our findings aim to create new knowledge to guide clinical decisions about the characteristics of patients with HF taking part in exercise-based CR.

\section{METHODS}

This study used a robust observational methodology to evaluate the potential contribution of individual patient characteristics in defining physical fitness in patients with HF attending a CR assessment.

\section{Data}

The study used data from a routinely collected audit of CR, British Heart Foundation (BHF) and the National Audit of Cardiac Rehabilitation (NACR). The NACR collects data from CR programmes across the UK and has a $74 \%$ coverage for electronic data entry. ${ }^{3}$ The electronic data were acquired in a link-anonymised format from 224 programmes, which collect data on patient's demographics, risk factors and baseline measures prior to starting CR. The data collection of patient information is covered by Section 251 approval which is reviewed by NHS Digital annually, the rationale for data collection was to improve the quality of CR service delivery for public benefit. Patients were included if they had an initiating event (primary diagnosis of HF) between 1 January 2013 and 30 October 2018. To account for potential reporting bias through missing data, the HF population without an ISWT score was compared with the ISWT group in the context of age and gender. A planned subanalysis investigated the extent by which HF severity, defined by the NYHA Functional Classification, determined walking fitness.

The primary variable of interest (dependant variable) is maximum distance walked in metres measured by the ISWT as part of a prerehabilitation assessment. The ISWT is an externally paced (via audio player) and graded walk test with 12 levels of speed that has been validated in cardiac and pulmonary rehabilitation populations. ${ }^{1417}$ Although the test result can be reported by the speed level achieved our planned analysis used distance walked as a continuous variable in the linear regression model which also enabled us to pursue reference values using a measure (metres walked) which are more relevant to clinicians and patients.

\section{Statistical analysis}

The analyses were conducted in IBM statistical package SPSS V.25 (SPSS). Correlation and group comparisons used t-tests and Pearson correlation, respectively. Subject to having sufficient data to fulfil statistical distribution assessments $(n>30)$ all potential covariates were investigated in the analysis. Backwards stepwise linear regression models were built to investigate whether, accounting for covariates, the patient-level factors were associated with walking fitness as measured by ISWT distance.

Relevant important covariates were included in the analysis, where they were evidenced in the literature or significant in preliminary analysis. Age (years), gender (male/female), marital status (single/not) and employment status have been shown to influence the outcomes following a variety of different rehabilitation interventions, including CR. Employment status was coded as employed/retired or unemployed, this is because previous research found that employed and retired states have similar effects on outcomes. Other risk factors such as BMI, physical activity, smoking status, psychosocial well-being measured through Hospital Anxiety Depression Scale (HADS) score and comorbidity were included as they are routinely reported by the NACR as variables that influence patient engagement with CR. ${ }^{38}$

Statistical level for significance was $\mathrm{p}<0.05$ and actual significant values were expressed as reported up to 0.001. Data model checking was performed to ensure that the models were a good fit through assumptions associated with the regressions.

\section{RESULTS}

This study consisted of 1519 patients (68\% male) with HF who had completed an ISWT. The mean age for total population was 64.5 (SD 12.7) years. Table 1 shows the average ISWT distances in metres for each of the included variables. The overall mean distance was 266.6 $\mathrm{m}$ (156.4 SD). Pearson correlation indicates that there is a significant negative relationship between age and 
Table 1 Incremental shuttle walk test (ISWT) distance for all included variables

\section{ISWT distance (m)}

\begin{tabular}{|c|c|c|c|c|c|c|}
\hline \multirow[b]{2}{*}{ Patient characteristics } & \multicolumn{6}{|c|}{ ISWT distance (m) } \\
\hline & Mean & SD & Count & $\%$ & $\begin{array}{l}\text { Pearson correlation } \\
\text { (PC)/mean difference } \\
\text { (MD)/F stat ANOVA (F) }\end{array}$ & $P$ value \\
\hline Age & 64.51 & 12.70 & 1519 & & $-0.40(\mathrm{PC})$ & $<0.001$ \\
\hline \multicolumn{7}{|l|}{ Gender } \\
\hline Male & 284.3 & 162.65 & 1035 & 68 & \multirow[t]{2}{*}{55.71 (MD) } & \multirow[t]{2}{*}{$<0.001$} \\
\hline Female & 228.6 & 134.94 & 482 & 32 & & \\
\hline \multicolumn{7}{|l|}{ Ethnicity } \\
\hline White & 263.7 & 151.47 & 1136 & 75 & \multirow[t]{2}{*}{$-11.74(\mathrm{MD})$} & \multirow[t]{2}{*}{0.204} \\
\hline Non-white & 275.4 & 170.15 & 383 & 25 & & \\
\hline \multicolumn{7}{|l|}{ Smoking Status } \\
\hline No & 266.5 & 153.31 & 1304 & 93 & \multirow[t]{2}{*}{$-10.61(\mathrm{MD})$} & \multirow[t]{2}{*}{0.503} \\
\hline Yes & 277.1 & 179.31 & 104 & 7 & & \\
\hline \multicolumn{7}{|l|}{ Physical activity status } \\
\hline No & 246.5 & 153.92 & 887 & 68 & \multirow[t]{2}{*}{$-60.85(\mathrm{MD})$} & \multirow[t]{2}{*}{$<0.001$} \\
\hline Yes & 307.4 & 149.56 & 408 & 32 & & \\
\hline \multicolumn{7}{|l|}{ Body mass index (BMI) } \\
\hline$<30$ & 276.2 & 163.18 & 827 & 59 & \multirow[t]{2}{*}{25.42 (MD) } & \multirow[t]{2}{*}{0.002} \\
\hline$>30$ & 250.8 & 138.64 & 586 & 41 & & \\
\hline \multicolumn{7}{|l|}{ Employment status } \\
\hline Employed & 262.5 & 152.63 & 995 & 79 & \multirow[t]{2}{*}{$-9.53(\mathrm{MD})$} & \multirow[t]{2}{*}{0.366} \\
\hline Unemployed & 272.1 & 156.78 & 266 & 21 & & \\
\hline \multicolumn{7}{|l|}{ Marital status } \\
\hline Single & 246.9 & 157.08 & 359 & 31 & \multirow[t]{2}{*}{-19.36 (MD) } & \multirow[t]{2}{*}{0.039} \\
\hline Partner & 266.2 & 143.44 & 799 & 69 & & \\
\hline \multicolumn{7}{|l|}{ HADS score: Anxiety } \\
\hline Not anxious & 271.6 & 155.81 & 1042 & 83 & \multirow[t]{2}{*}{36.79 (MD) } & \multirow[t]{2}{*}{0.002} \\
\hline Anxious & 234.8 & 145.82 & 209 & 17 & & \\
\hline \multicolumn{7}{|l|}{ HADS score: Depression } \\
\hline Not depressed & 274.2 & 154.71 & 1082 & 86 & 64.78 (MD) & $<0.001$ \\
\hline Depressed & 209.4 & 143.38 & 169 & 14 & & \\
\hline IMD score & & & & & & \\
\hline Lowest quintile & 265.5 & 173.68 & 263 & 22.1 & $0.43(F)$ & 0.789 \\
\hline Second quintile & 256.6 & 163.18 & 277 & 23.3 & & \\
\hline Third quintile & 259.6 & 144.28 & 221 & 18.6 & & \\
\hline Fourth quintile & 267.9 & 157.85 & 232 & 19.5 & & \\
\hline Fifth quintile & 274.3 & 161.18 & 196 & 16.5 & & \\
\hline Total population ISWT score & 266.6 & 156.41 & & & & \\
\hline
\end{tabular}

ANOVA, analysis of variance; HADS, Hospital Anxiety Depression Scale; IMD, Index of Multiple Deprivation; MD, mean difference; PC, pearson correlation.

ISWT distance of $-0.40(p \leq 0.001)$, which was stronger for females $(\mathrm{r}=-0.436)$ than males $(\mathrm{r}=-0.391)$.

In absolute terms males had a significantly larger ISWT distance on average $55.7 \mathrm{~m}$ greater than females $(p \leq 0.001)$. Patients with a history of achieving moderate physically active status had on average a statistically significant $60.9 \mathrm{~m}$ greater distance than those who were not $(\mathrm{p} \leq 0.001)$. Patients with BMI greater than 30 demonstrated shorter ISWT distances by on average $25.4 \mathrm{~m}(\mathrm{p}=0.002)$. Marital status of patients was 
significantly associated with walking fitness, those with a partner had $19.4 \mathrm{~m}$ greater than those single $(\mathrm{p}=0.039)$. No other variables were associated with differences in ISWT distance. Patients who were either anxious or depressed at baseline, HADS score $\geq 8$, had significantly lower walking distances than those patients with HADS score below $8(\mathrm{p}<0.05)$.

Additionally, the study included as subset analysis the inclusion of NYHA class I-IV, the analysis failed to find any significant differences between the NYHA class and ISWT distance $(\mathrm{p}>0.05)$.

Table 2 shows the ISWT distance, when analysed against the patient's comorbidity status. Eighteen comorbidities captured on the NACR were included, along with a single-variable coding multimorbidity of $\leq 3$ or $3+$. The results showed that patients having angina, arthritis, diabetes, stroke, hypertension, chronic obstructive pulmonary disease (COPD), asthma and chronic back problems demonstrated significantly lower ISWT distance (mean difference range 28.2-55.3, $\mathrm{p}<0.05)$.

The number of comorbidities was also significant with a $42.19 \mathrm{~m}$ reduced mean difference with having more than three comorbidities.

Table 3 shows the results from the linear regression evaluating the association between ISWT distance against patient characteristics and related risk factors. The model confirms that age, after accounting for multiple potential confounders, was negatively associated ISWT distance $(\mathrm{B}=-4.868, \mathrm{p}<0.001)$. The effect of age is centralised around the mean suggesting that for each single-year increase in age, above the mean, there is an associated $5.5 \mathrm{~m}$ reduction in distance walked.

Gender plays a significant part in determining walking fitness with female patients having a $42 \mathrm{~m}$ reduced walking distance $(p<0.001)$. Other covariates of statistical significance associated were ethnicity, employment status, marital status, physical activity, BMI and socioeconomic class. Patients being unemployed, with greater BMI and not achieving physical activity status were all associated with a lower ISWT score between 29 and 50 $\mathrm{m}(\mathrm{p}=0.05-0.001)$. For every increase in socioeconomic class quintile the patient's baseline ISWT increased by $8.5 \mathrm{~m}$, thus being from the lowest as opposed to the highest quintiles was a difference of $44 \mathrm{~m}(\mathrm{p}=0.002)$. Patients being identified as clinically or borderline depressed at baseline using the HADS score performed on average $52 \mathrm{~m}$ worse than those who were classified as normal $(\mathrm{p}<0.001)$.

Variables that were not significant such as smoking status, other covariates and multimorbidity were automatically removed from the backward stepwise analysis.

The model was of good fit and the residuals met the assumptions of uniform variance and linearity, and the adjusted $r^{2}$ value was 0.266 . The grouping of comorbidities into less than or greater than 3 was not significantly associated with walking fitness. Subset analysis showed that the model with NYHA was not of greater fit. The inclusion of NYHA class was not statistically significant.

Table 4 presents our proposed reference values for ISWT distance split by age, gender and COPD set within 5, 25, 75 and 95 percentiles.

\section{DISCUSSION}

Reassuringly our findings showed that patients with a primary diagnosis of HF, referred to CR, were capable of levels of walking fitness, achieved through challenging incremental test, comparable to the 25th-50th centiles of patients with conventional cardiovascular disease attending CR. ${ }^{17}$ Although the extent of walking fitness was greater by $42 \mathrm{~m}$ in the group with fewer comorbidities $(\leq 3)$, a good mean distance of $240 \mathrm{~m}$ was achieved in the group having greater than three additional comorbidities. These findings help establish a positive picture in terms of physical fitness for those patients with the diagnosis of $\mathrm{HF}$ and willingness to engage in rehabilitation.

Using mean age of the study population $(64.5 \pm 12.7)$ as a reference value, being older by 1 year was significantly associated with reduced walking distances in the region of $4.9 \mathrm{~m}$ for each year above mean age. This relationship is not new as it is evident in the conventional CR patient populations ${ }^{1617}$; however, the ability to quantify the extent of loss, with increasing age, represents a novel finding in patients with HF.

After accounting for comorbidities gender continues to play a significant part in determining walking fitness with female patients having a $42 \mathrm{~m}$ reduced walking distance. The CR literature and routine practice data, captured in national reports, ${ }^{3}$ highlight that around $80 \%$ of patients with $\mathrm{HF}$ are missing out on CR and of those who do attend around one-third have a recorded physical fitness assessment. ${ }^{311}$ National clinical guidance worldwide recommends assessment of physical fitness prior to starting $\mathrm{CR}^{6713}$ yet two-thirds of patients in the UK are not assessed. In terms of HF the lack of physical assessment may not purely be the fault of programmes and could, in part, be explained by the incapacity of patients or in some cases a perceived incapacity to carry out a walk test especially an incremental test. Our research has produced reference values to help clarify physical fitness expectations for patients with HF attending CR and for clinicians to aid goal setting at the start of CR (table 4).

A knowledge of age and gender differences in walking fitness aligned with fitness determining comorbidities such as COPD and depression, as shown in table 4, is considered useful in clarifying HF-specific physical fitness expectations for CR programme staff, patients and carers.

The presence of COPD in the form of chronic bronchitis or emphysema is significant in predicting fitness in patients with $\mathrm{HF}$ resulting in a $39 \mathrm{~m}$ reduction walking distance. COPD is dominated by the symptom 
Cardiac risk factors and prevention

Table 2 Incremental shuttle walk test (ISWT) distance reported by comorbidity category

\begin{tabular}{|c|c|c|c|c|c|c|}
\hline \multirow{3}{*}{$\begin{array}{l} \\
\text { Angina }\end{array}$} & \multicolumn{6}{|c|}{ ISWT distance (m) } \\
\hline & Mean & SD & \multirow[t]{2}{*}{ Count } & \multirow[t]{2}{*}{$\%$} & \multirow[t]{2}{*}{ Mean difference } & \multirow[t]{2}{*}{$P$ value } \\
\hline & \multicolumn{2}{|l|}{ 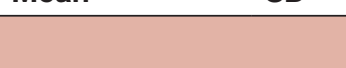 } & & & & \\
\hline No & 270.0 & 158.5 & 1419 & 93 & 51.6 & 0.001 \\
\hline Yes & 218.5 & 114.1 & 110 & 7 & & \\
\hline \multicolumn{7}{|c|}{ Arthritis } \\
\hline No & 276.3 & 158.3 & 1262 & 83 & 57.1 & $<0.001$ \\
\hline Yes & 219.2 & 137.5 & 257 & 17 & & \\
\hline \multicolumn{7}{|c|}{ Cancer } \\
\hline No & 268.6 & 158.7 & 1383 & 91 & 22.0 & 0.117 \\
\hline Yes & 246.6 & 130.2 & 136 & 9 & & \\
\hline \multicolumn{7}{|c|}{ Diabetes } \\
\hline No & 276.7 & 161.1 & 1207 & 79 & 48.8 & $<0.001$ \\
\hline Yes & 227.9 & 129.9 & 312 & 21 & & \\
\hline \multicolumn{7}{|c|}{ Stroke } \\
\hline No & 270.0 & 158.0 & 1424 & 94 & 53.1 & 0.001 \\
\hline Yes & 216.9 & 120.6 & 95 & $6 \%$ & & \\
\hline \multicolumn{7}{|c|}{ Hypertension } \\
\hline No & 276.6 & 164.1 & 982 & 65 & 28.2 & 0.001 \\
\hline Yes & 248.4 & 139.6 & 537 & 35 & & \\
\hline \multicolumn{7}{|c|}{ Chronic obstructive pulmonary disease } \\
\hline No & 270.6 & 157.8 & 1409 & 93 & 55.3 & 0.001 \\
\hline Yes & 215.4 & 126.9 & 110 & 7 & & \\
\hline \multicolumn{7}{|c|}{ Asthma } \\
\hline No & 269.2 & 157.8 & 1394 & 92 & 31.4 & 0.031 \\
\hline Yes & 237.8 & 137.1 & 125 & 8 & & \\
\hline \multicolumn{7}{|c|}{ Chronic back problems } \\
\hline No & 272.0 & 158.5 & 1306 & 86 & 38.1 & 0.001 \\
\hline Yes & 233.8 & 138.7 & 213 & 14 & & \\
\hline \multicolumn{7}{|c|}{ Anxiety } \\
\hline No & 265.8 & 156.0 & 1402 & 92 & -11.4 & 0.449 \\
\hline Yes & 277.2 & 161.9 & 117 & 8 & & \\
\hline \multicolumn{7}{|c|}{ Depression } \\
\hline No & 268.3 & 158.8 & 1372 & 90 & 16.8 & 0.217 \\
\hline Yes & 251.5 & 131.4 & 147 & 10 & & \\
\hline \multicolumn{7}{|c|}{ Family history } \\
\hline No & 266.0 & 159.1 & 1253 & 82 & -3.5 & 0.741 \\
\hline Yes & 269.5 & 143.1 & 266 & 18 & & \\
\hline \multicolumn{7}{|c|}{ Erectile dysfunction } \\
\hline No & 267.3 & 157.4 & 1436 & 95 & 12.9 & 0.466 \\
\hline Yes & 254.5 & 138.5 & 83 & 5 & & \\
\hline \multicolumn{7}{|c|}{ Hypercholesterolaemia/dislipidaemia } \\
\hline No & 269.0 & 159.0 & 1280 & 84 & 15.3 & 0.166 \\
\hline Yes & 253.8 & 141.7 & 239 & 16 & & \\
\hline \multicolumn{7}{|c|}{ Comorbidities grouped } \\
\hline$\leq 3$ & 282.0 & 166.0 & 967 & 64 & 42.2 & $<0.001$ \\
\hline$>3$ & 239.8 & 134.1 & 552 & 36 & & \\
\hline
\end{tabular}

Osteoporosis, claudication and rheumatism were removed due to insufficient subset sample sizes $(n \leq 25)$. 
Table 3 Linear regression findings for the incremental shuttle walk test (ISWT) by patient characteristics

\begin{tabular}{|c|c|c|c|c|c|}
\hline Patient characteristics & B & SE & $\mathbf{t}$ & Significance & $95 \% \mathrm{Cl}$ \\
\hline Gender (Female) & -42.123 & 10.658 & -3.952 & $<0.001$ & -63.055 to -21.191 \\
\hline Age & -4.868 & 0.447 & -10.888 & $<0.001$ & -5.746 to -3.990 \\
\hline Ethnicity (Non-white) & -23.347 & 13.340 & -1.750 & 0.081 & -49.545 to 2.852 \\
\hline Physical activity status (150 min/week) & 43.467 & 10.543 & 4.123 & $<0.001$ & 22.761 to 64.173 \\
\hline $\mathrm{BMI}(>30)$ & -28.645 & 10.203 & -2.808 & 0.005 & -48.682 to -8.607 \\
\hline Employment status (Unemployed) & -50.336 & 12.951 & -3.887 & $<0.001$ & -75.771 to -24.901 \\
\hline Diabetes & -33.448 & 12.318 & -2.715 & 0.007 & -57.639 to -9.257 \\
\hline Chronic back problems (Yes) & -36.855 & 13.392 & -2.752 & 0.006 & -63.155 to -10.554 \\
\hline COPD (Yes) & -39.310 & 18.937 & -2.076 & 0.038 & -76.501 to -2.119 \\
\hline HADS score: Depression (Depressed) & -52.194 & 14.842 & -3.517 & $<0.001$ & -81.342 to -23.045 \\
\hline IMD score & 11.624 & 3.801 & 3.058 & 0.002 & 4.160 to 19.088 \\
\hline Intercept & 276.703 & 13.339 & 20.744 & $<0.001$ & 250.506 to 302.899 \\
\hline
\end{tabular}

$R=0.530 . R^{2}=0.281$. Adj $R^{2}=0.266$.

BMI, body mass index; COPD, chronic obstructive pulmonary disease; HADS, Hospital Anxiety Depression Scale; IMD, Index of Multiple Deprivation.

of breathlessness, at rest, and exacerbated by physical effort which on top of the diagnosis of HF possibly explains such lower levels of fitness. ${ }^{18}$ The severity of $\mathrm{HF}$ as measured by NYHA did not reach significance as a determinant which might be explained by the analysis accounting for COPD. Within the NYHA class groups the proportion with COPD was $4 \%$ for class 1 , $5 \%$ for class $2,11 \%$ for class $3 \%$ and $31 \%$ for class 4 . The inter-relation between HF and COPD is becoming increasingly important clinically leading to a call for a service provision aimed at managing breathlessness in patients with these comorbidities. ${ }^{18}$

A new finding for patients with HF was that higher levels of depression, measured using HADS, were strongly associated with poorer walking fitness. This has not been investigated previously in HF; however, our findings concur with a robust systematic review in healthy and depressed adult populations where depression and physical fitness were found to be inversely correlated. ${ }^{19}$

Table 4 incorporates the impact of COPD and depression on walking fitness reference values for younger and older patients with the combination of $\mathrm{HF}+\mathrm{COPD}$ or $\mathrm{HF}+$ depression. This is the first set of reference values to account for the presence of such variables alongside HF which should enable clinicians to better understand physical fitness differences and/or expectations of their patients.

Our findings have generated new knowledge to help guide clinical decisions about the suitability of patients with HF to take part in exercise-based CR. The study also produced a set of reference values aligned with

Table 4 Incremental shuttle walk test reference values for patients with heart failure (HF) split by age, gender and presence of chronic obstructive pulmonary disease (COPD) and depression

\begin{tabular}{|c|c|c|c|c|c|c|c|c|}
\hline \multirow[b]{2}{*}{$\begin{array}{l}\text { Heart failure } \\
\text { (HF)+comorbidity } \\
\text { category }\end{array}$} & \multirow[b]{2}{*}{ Age and gender } & \multicolumn{6}{|c|}{ Incremental shuttle walk test (ISWT) } & \multirow[b]{2}{*}{ Count } \\
\hline & & $\begin{array}{l}\text { Mean } \\
\text { distance } \\
(\mathrm{m})\end{array}$ & SD & Percentile 05 & Percentile 25 & Percentile 75 & Percentile 95 & \\
\hline \multirow[t]{5}{*}{ HF only } & $<67$ years & & & & & & & \\
\hline & Male & 338 & 180 & 70 & 200 & 460 & 630 & 443 \\
\hline & Female & 285 & 145 & 70 & 190 & 350 & 520 & 190 \\
\hline & Male & 243 & 138 & 60 & 140 & 330 & 480 & 434 \\
\hline & Female & 184 & 109 & 40 & 100 & 250 & 390 & 211 \\
\hline \multirow[t]{2}{*}{$\mathrm{HF}+\mathrm{COPD}$} & $<67$ years & 237 & 133 & 40 & 120 & 330 & 430 & 51 \\
\hline & $67+$ years & 197 & 120 & 40 & 90 & 270 & 470 & 59 \\
\hline
\end{tabular}


age, gender, COPD and depression to aid the interpretation of walking fitness in patients with HF in the hope that this new knowledge will help improve referral and uptake to CR.

\section{Limitations}

Although the study investigated a large number of covariates, we were unable to account for medications such as diuretics and beta-blockers that may have accounted for some variation within the population in terms of weight gain and walking fitness, respectively.

Concerning our subanalysis of HF severity using NYHA there was a potential reporting bias through missing data. Although we cannot rule this out our analysis of the population with and without a recorded NYHA classification showed no significant differences for age and gender.

The mean age of patients recruited was 64.5 (SD 12.7) years which is below that seen in the general $\mathrm{HF}$ population. Our approach to ISWT reference values utilises the median distribution above and below 67 years which better reflects the full range of patients.

\section{CONCLUSION}

The study concludes that patient age, gender, ethnicity, physical activity and depression status, along with the presence of COPD as comorbidity, were significant factors in predicting walking fitness in patients with HF. This is the first study to clarify the extent by which patient characteristics determine walking fitness in patients with $\mathrm{HF}$ and these findings have the potential to aid clinician understanding of the levels of fitness patients with HF can achieve. The study produced a novel set of reference values, aligned with age, gender, COPD and depression, to aid the interpretation of walking fitness by clinicians and patients. Through dissemination of these findings we believe this knowledge has potential to improve confidence in clinicians making a referral to CR and lead to a greater number of patients undergoing a physical fitness assessment thus enabling an appropriate exercise prescription.

Contributors The three authors listed are the sole contributors to the research and all were included in the conception, analysis and writing of the manuscript.

Funding This study and the NACR data is funded by the British Heart Foundation grant (040/PSS/17/18/NACR).

Competing interests None declared.

Patient consent for publication Not required.

Provenance and peer review Not commissioned; externally peer reviewed.

Data sharing statement The data used were from the NACR which, due to it being link anonymised with Section 251 approval, cannot be shared publicly.

Open access This is an open access article distributed in accordance with the Creative Commons Attribution 4.0 Unported (CC BY 4.0) license, which permits others to copy, redistribute, remix, transform and build upon this work for any purpose, provided the original work is properly cited, a link to the licence is given, and indication of whether changes were made. See: https://creativecommons.org/ licenses/by/4.0/.

\section{REFERENCES}

1. Anderson L, Oldridge N, Thompson DR, et al. Exercise-Based Cardiac Rehabilitation for Coronary Heart Disease. J Am Coll Cardiol 2016;67:1-12.

2. Sagar VA, Davies EJ, Briscoe S, et al. Exercise-based rehabilitation for heart failure: systematic review and meta-analysis. Open Heart 2015;2: 000163.

3. 2018. National Audit of Cardiac Rehabilitation: annual statistical report 2017. Available from: https://www.bhf.org.uk/publications/ statistics/national-audit-of-cardiac-rehabilitation-annual-statisticalreport-2017 [Accessed 27 Feb 2018].

4. NICE CG172, 2013. Myocardial infarction: cardiac rehabilitation and prevention of further cardiovascular disease. Clinical guideline [CG172]. Available from: https://www.nice.org.uk/guidance/cg172 [Accessed $27 \mathrm{Feb} 2018$ ].

5. National Institute for Health and Care Excellence. Chronic heart failure in adults: diagnosis and management (NICE guideline NG106), 2018. Available: https://www.nice.org.uk/guidance/ng106 [Accessed 02 Jan 2019].

6. Piepoli MF, Corrà U, Adamopoulos $\mathrm{S}$, et al. Secondary prevention in the clinical management of patients with cardiovascular diseases. Core components, standards and outcome measures for referral and delivery: a policy statement from the cardiac rehabilitation section of the European Association for Cardiovascular Prevention \& Rehabilitation. Endorsed by the Committee for Practice Guidelines of the European Society of Cardiology. Eur J Prev Cardiol 2014;21:664-81.

7. Ades PA, Keteyian SJ, Wright JS, et al. Increasing cardiac rehabilitation participation from $20 \%$ to $70 \%$ : a road map from the Million Hearts Cardiac Rehabilitation Collaborative. Mayo Clin Proc 2017;92:234-42.

8. Al Quait A, Doherty P, Gutacker N, et al. In the modern era of percutaneous coronary intervention: Is cardiac rehabilitation engagement purely a patient or a service level decision? Eur J Prev Cardiol 2017:24:1351-7.

9. Bjarnason-Wehrens B, McGee H, Zwisler AD, et al. Cardiac rehabilitation in Europe: results from the European Cardiac Rehabilitation Inventory Survey. Eur J Cardiovasc Prev Rehabil 2010;17:410-8.

10. Peters AE, Keeley EC. Trends and Predictors of Participation in Cardiac Rehabilitation Following Acute Myocardial Infarction: Data From the Behavioral Risk Factor Surveillance System. J Am Heart Assoc 2018;7:e007664.

11. NICOR, 2018. National Heart Failure Audit 2017. Available from: http://www.ucl.ac.uk/nicor/audits/heartfailure [Accessed 27 Feb 2018].

12. Dalal HM, Doherty P, Taylor RS. Cardiac rehabilitation. BMJ 2015;351:h5000-8.

13. British Association for Cardiovascular Prevention and Rehabilitation (BACPR), 2017. Standards and Core Components for Cardiovascular Disease Prevention and Rehabilitation. Available from: http://www. bacpr.com/resources/BACPR_Standards_and_Core_Components 2017.pdf [Accessed 20 Oct 2017].

14. Fowler SJ, Singh SJ, Revill S. Reproducibility and validity of the incremental shuttle walking test in patients following coronary artery bypass surgery. Physiotherapy 2005;91:22-7.

15. Pepera G, McAllister J, Sandercock G. Long-term reliability of the incremental shuttle walking test in clinically stable cardiovascular disease patients. Physiotherapy 2010;96:222-7.

16. Cardoso FM, Almodhy M, Pepera G, et al. Reference values for the incremental shuttle walk test in patients with cardiovascular disease entering exercise-based cardiac rehabilitation. J Sports Sci 2017;35:1-6.

17. Alotaibi JFM, Doherty P. Evaluation of determinants of walking fitness in patients attending cardiac rehabilitation. BMJ Open Sport Exerc Med 2017;2:e000203:1-16.

18. Man WD, Chowdhury F, Taylor RS, et al. Building consensus for provision of breathlessness rehabilitation for patients with chronic obstructive pulmonary disease and chronic heart failure. Chron Respir Dis 2016:13:229-39.

19. Papasavvas T, Bonow RO, Alhashemi M, et al. Depression Symptom Severity and Cardiorespiratory Fitness in Healthy and Depressed Adults: A Systematic Review and Meta-Analysis. Sports Med 2016;46:219-30. 


\section{Correction: Determinants of walking fitness in patients with heart failure attending cardiac rehabilitation}

Doherty P, Harrison AS, Hossain R. Determinants of walking fitness in patients with heart failure attending cardiac rehabilitation. Open Heart 2019;6:e000866. doi: 10.1136/ openhrt-2018-000866

The authors want to alert readers to the following errors were identified in the published version.

At page 6 Table 4, the values under first data column 'mean distance' is incorrect and needs to be removed (ie, to remove the values 268, 194, 237 and 181 from the table). And shift the four rows to the left which will leave the column 'Count' empty and these should be filled with the following values: 51, 59, 95 and 52.

The Table 4 should read as below:

Table 4 Incremental shuttle walk test reference values for heart failure (HF) patients split by age, gender and presence chronic obstructive pulmonary disease (COPD) and depression

\begin{tabular}{|c|c|c|c|c|c|c|c|c|c|}
\hline \multirow{2}{*}{$\begin{array}{l}\text { Heart } \\
\text { failure (HF) } \\
\text { +comorbidity } \\
\text { category }\end{array}$} & & & \multicolumn{6}{|c|}{ Incremental shuttle walk test (ISWT) } & \multirow[b]{2}{*}{ Count } \\
\hline & \multicolumn{2}{|c|}{ Age \& Gender } & $\begin{array}{l}\text { Mean } \\
\text { distance } \\
\text { (metres) }\end{array}$ & SD & $\begin{array}{l}\text { Percentile } \\
05\end{array}$ & $\begin{array}{l}\text { Percentile } \\
25\end{array}$ & $\begin{array}{l}\text { Percentile } \\
75\end{array}$ & $\begin{array}{l}\text { Percentile } \\
95\end{array}$ & \\
\hline \multirow[t]{4}{*}{ HF only } & \multirow{2}{*}{$\begin{array}{l}<67 \\
\text { years }\end{array}$} & Male & 338 & 180 & 70 & 200 & 460 & 630 & 443 \\
\hline & & Female & 285 & 145 & 70 & 190 & 350 & 520 & 190 \\
\hline & \multirow[t]{2}{*}{$67+$ years } & Male & 243 & 138 & 60 & 140 & 330 & 480 & 434 \\
\hline & & Female & 184 & 109 & 40 & 100 & 250 & 390 & 211 \\
\hline \multirow[t]{2}{*}{$\mathrm{HF}+\mathrm{COPD}$} & \multicolumn{2}{|l|}{$<67$ years } & 237 & 133 & 40 & 120 & 330 & 430 & 51 \\
\hline & \multicolumn{2}{|l|}{$67+$ years } & 197 & 120 & 40 & 90 & 270 & 470 & 59 \\
\hline \multirow[t]{2}{*}{ HF +Depression } & \multicolumn{2}{|l|}{$<67$ years } & 261 & 143 & 30 & 150 & 340 & 520 & 95 \\
\hline & \multicolumn{2}{|l|}{$67+$ years } & 233 & 107 & 70 & 155 & 295 & 420 & 52 \\
\hline
\end{tabular}

Open access This is an open access article distributed in accordance with the Creative Commons Attribution 4.0 Unported (CC BY 4.0) license, which permits others to copy, redistribute, remix, transform and build upon this work for any purpose, provided the original work is properly cited, a link to the licence is given, and indication of whether changes were made. See: https:// creativecommons.org/licenses/by/4.0/.

(C) Author(s) (or their employer(s)) 2019. Re-use permitted under CC BY. Published by BMJ.

Open Heart 2019;6:000866. doi:10.1136/openhrt-2018-000866corr1

A) Check for updates 